Article

\title{
Increasing Dietary Carbohydrate as Part of a Healthy Whole Food Diet Intervention Dampens Eight Week Changes in Salivary Cortisol and Cortisol Responsiveness
}

\author{
Hoda Soltani ${ }^{1}$, Nancy L. Keim ${ }^{1,2}$ and Kevin D. Laugero ${ }^{1,2, *}$ \\ 1 Department of Nutrition, University of California, Davis, CA 95616 1, USA; hsoltani@ucdavis.edu (H.S.); \\ nancy.keim@ars.usda.gov (N.L.K.) \\ 2 Obesity and Metabolism Research Unit, USDA/ARS/Western Human Nutrition Research Center 2, Davis, \\ CA, 95616, USA \\ * Correspondence: kevin.laugero@ars.usda.gov; Tel.: +1-530-752-4173
}

Received: 18 September 2019; Accepted: 22 October 2019; Published: 24 October 2019

\begin{abstract}
It is largely unknown whether and how whole food diets influence psychological stress and stress system responsiveness. To better understand the effects of whole diets on stress system responsiveness, we examined randomized control trial effects of a whole food diet based on the Dietary Guidelines for Americans (DGA) on cortisol responsiveness. A randomized, double-blind, controlled 8-week intervention was conducted in overweight and obese women to examine differentiated effects between two diet intervention groups: one based on the 2010 DGA and the other one based on a typical American diet (TAD). During a test week that occurred at baseline and again after 8 weeks of the intervention, we assessed salivary cortisol collected at 14 selected times across the day, including upon awakening, at bedtime, and during a test visit, and administered a standardized social stress task (Trier Social Stress Test, TSST). There were no statistical differences between the diet groups in salivary cortisol at baseline or after 8 weeks. However, when considering differences in dietary carbohydrate, but not fat or protein, from the pre-intervention (habitual) to the intervention period, there was a significant $(P=0.0001)$ interaction between diet group, intervention week, saliva sample, and level of intervention-based change in carbohydrate consumption. This interaction was reflected primarily by an 8 -week reduction in salivary cortisol during a period just prior to $(\log \Delta-0.35 \pm 0.12 \mathrm{nmol} / \mathrm{L})$ and $30(\log \Delta-0.49 \pm 0.12 \mathrm{nmol} / \mathrm{L}), 60(\log \Delta-0.50 \pm 0.13 \mathrm{nmol} / \mathrm{L}), 90(\log \Delta-0.51 \pm 0.13 \mathrm{nmol} / \mathrm{L})$, and $120(\log \Delta-0.4476 \pm 0.1231 \mathrm{nmol} / \mathrm{L}) \mathrm{min}$ after the TSST in the DGA group having the highest increase (90th percentile) in carbohydrate consumption. In support of this finding, we also found significant $(P<0.05)$ and inverse linear associations between dietary carbohydrate and log salivary cortisol, with the strongest negative association $(\beta$ : $-0.004 \pm 0.0015, P=0.009)$ occurring at $30 \mathrm{~min}$ post-TSST, but only in the DGA group and at week 9 of the intervention. Together, increasing dietary carbohydrate as part of a DGA-based diet may reduce circulating cortisol and dampen psychological stress-related cortisol responsiveness.
\end{abstract}

Keywords: diet intervention; dietary guidelines; dietary carbohydrate; salivary cortisol; Trier Social Stress Test

\section{Introduction}

While a healthy diet is often recommended as a strategy for managing stress and stress-related diseases, there are no evidence-based, specific dietary guidelines that target such concerns. There is a growing awareness about the advantages of nutritional medicine in psychiatry [1], prompting 
an increased focus on the interrelationships between stress, mood, and nutrition. Several studies have shown the influence of nutrients and specific foods on an individual's physiological, neural, and psychological stress response [2-16]. For example, high-fat feeding increases circulating corticosterone in rodent models $[17,18]$, and high-fat meals were shown to exacerbate detrimental autonomic nervous systems and cardiovascular responses to stress [8]. In contrast, polyunsaturated fat intake can diminish stress-induced cardiovascular responses [3], omega-3 fatty acid consumption normalized abnormally low cortisol responses to an acute stress test [6], and milk-based phospholipids improved memory in men reporting high levels of chronic stress [14]. In addition, adding egg powder to the diet normalized the endocrine and the negative emotional response to stress, which thereby normalized neuroendocrine stress responses and reduced adaptation to acute stress [15].

It was also shown that consumption of fermented foods is associated with reduced social anxiety [19]. Finally, dietary sugar or carbohydrate may dampen stress-induced elevation in glucocorticoid hormones, such as corticosterone (rodents) and cortisol (human) [20-24], a phenomenon thought to physiologically explain and strengthen comfort eating or the stress-eating relationship [25,26]. However, little is known about how whole food diets, such as those based on the Dietary Guidelines for Americans (DGA), may impact daily cortisol and cortisol responsiveness.

Despite the potential for whole food diets, such as those based on DGA standards, to mitigate the magnitude of stress reactions, DGA adherence is typically poor $[27,28]$. Furthermore, diet interventions intended to diminish cardiometabolic issues are often limited by individuals' dietary and weight relapse in the long term [29]. This is unfortunate given the fact that those who can sustainably adopt a diet based on DGA recommendations have a diminished risk for developing obesity-related diseases, such as type 2 diabetes [30-32]. Regression to previous eating behaviors is linked to neurological factors associated with psychological, emotional, and cognitive functions [33-36]. In fact, adopting new dietary patterns can trigger psychological stress and its associated increases in cortisol $[37,38]$ which, in turn, can limit progress in making these dietary changes sustainable $[39,40]$ and thereby limit the overall effectiveness of dietary recommendations.

Psychological stress can adversely influence the quality of food choices, weight loss, and metabolic health [41]. Feelings of stress can stimulate desire to consume highly palatable, calorically dense food and simultaneously disturb self-regulation and goal-directed decision-making by diminishing the cognitive processes that underlie them [42]. Reward-based eating and reactionary eating can be heightened by disruptions of homeostatic regulation of food intake induced by stress [43,44]. The ability to self-regulate behaviors and consciously make choices that favor long-term outcomes over short-term rewards is important for supporting long-term health and dietary behavior changes, particularly in the context of stress [45]. Given reports suggesting the increasing prevalence of stress $[46,47]$ and availability of highly palatable but nutritionally poor foods $[48,49]$, it is important to evolve the current understanding of stress networks controlling motivation. Such an understanding may assist in developing effective nutrition and disease prevention messaging and hopefully translate to assisting the public in making meaningful and durable improvements to their diet, irrespective of life's daily hassles.

To better understand the effects of whole diets on daily cortisol and cortisol responsiveness, we examined, in a randomized control trial, effects of a DGA-based diet on salivary cortisol throughout the day and in response to a standardized stress test, the Trier Social Stress Test. Exploratory analyses were also performed to assess if the magnitude of departure from the participants' usual pre-intervention dietary carbohydrate, fat, and protein mediated the effects of the intervention diet on salivary cortisol. A primary report on the effect of the intervention regarding clinical risk factors for type 2 diabetes and cardiovascular disease was recently published [50]. 


\section{Materials and Methods}

\subsection{Study Design}

This report was derived from a secondary analysis based on women who participated in a study reported by Krishnan et al. [50], in which the whole food diet consumption effects on cardiometabolic risk factors were measured. In this study, a randomized, double-blind, controlled 8-week fed intervention was conducted in overweight and obese women randomly assigned to one of two diet groups: a diet based on the 2010 DGA or a diet based on a typical American diet (TAD). Both DGA- and TAD-based diets were isocaloric and developed to maintain body weight over the 8-week intervention, while providing commonly available foods and beverages. The diets varied primarily in carbohydrates and sources of fat, with the DGA diet (56\% carbohydrates, $18 \%$ protein, and $26 \%$ fat) containing more whole grains, low-fat dairy, polyunsaturated fat, vegetables, and fruit, while the TAD-based diet (52\% carbohydrates, $15 \%$ protein, and 34\% fat) included more added sugars, refined grains, and solid and total fat. Krishnan et al. [50] published specific nutrient breakdown, sample menus, and key products used to prepare meals for each diet.

Study participants were informed that the research was investigating a broad set of factors that may contribute to understanding dietary effects on the body. Following orientation to the study, subjects were examined over a 1-week baseline (pre-intervention) period, during which they continued to consume their usual diets. This pre-intervention period was followed by the 8-week, meal-controlled diet intervention. During the pre-intervention period, physical activity, usual diet, energy requirements, body composition, cardiometabolic risk markers, and markers of psychological and physiological stress were estimated. These measurements were repeated at the end of the 8-week intervention. A detailed description of the study timeline and measurements performed in this study can be found in the publicatio-n by Krishnan et al. [50]. The trial was conducted at the Western Human Nutrition Research Center (WHNRC) in Davis, CA. The study was approved by Institutional Review Board at the University of California, Davis, and informed consent was given by subjects prior to participating in the study. This trial was approved by Davis Institutional Review Board in the University of California and is registered (NCT02298725) at clinicaltrials.gov. All participants provided written informed consent for participating in the study.

\subsection{Subjects}

Women, who were overweight or obese, aged 20-64, had a body mass index (BMI) of 25-39.9 kg/m², displayed either insulin resistance and/or dyslipidemia, and did not meet the minimal physical activity guidelines of $150 \mathrm{~min} /$ week, were recruited for the study. To determine eligibility during the screening process, study staff completed phone interviews where they verbally administered a telephone screening questionnaire. Potential participants were excluded if they were identified with any of the following characteristics: presence of any metabolic diseases, gastrointestinal disorders, cancer, or other serious chronic disease; pregnancy or lactating; current use of tobacco; prescribed or over-the-counter weight-loss medications in 6 months before enrollment into the study; moderate or strenuous physical activity of $>30 \mathrm{~min} /$ day on no less than 5 days per week; weight change of $>5 \%$ of body weight within 6 months of entry into the study; resting blood pressure of $>140 / 90 \mathrm{~mm}$ $\mathrm{Hg}$, hemoglobin of $<11.5 \mathrm{~g} / \mathrm{dL}$, total cholesterol of $>300 \mathrm{mg} / \mathrm{dL}$, Low Density Lipoprotein (LDL) cholesterol of $>189 \mathrm{mg} / \mathrm{dL}$, triglycerides of $>400 \mathrm{mg} / \mathrm{dL}$, and clinically abnormal thyroid or liver function; "graveyard" work shifts or forced to stay awake all night; dietary restrictions that would interfere with consuming the intervention foods; or use of corticosteroids and medications for elevated lipids or glucose. In addition, individuals considered to be vulnerable, including adults unable to consent, infants, children, and prisoners, were not eligible for the study. 


\subsection{Measurements}

\subsubsection{Dietary Measurements}

To approximate typical diet quality, subjects completed $24 \mathrm{~h}$ dietary recalls using an automated and self-administered system [51] during the pre-intervention period. Three unannounced $24 \mathrm{~h}$ dietary recalls were administered wherein participants input their intake for the previous $24 \mathrm{~h}$. Once entered, dietary data were quantified into specific nutrient and food categories, including the major macronutrients carbohydrate, fat, and protein, each of which was shown to influence stress-associated glucocorticoid concentrations $[17,52,53]$. Success in dieting or adopting new dietary habits may depend on an individual's eating behavior characteristics, making them more or less vulnerable to successful behavioral change. For example, certain characteristics such as restrained eating and disinhibition have been associated with increases in circulating concentrations of cortisol [54-56]. To help account for these eating behavior characteristics, we used the Three-Factor Eating Questionnaire (TFEQ) to assess hunger, restrained eating, and disinhibition. The TFEQ asks a series of questions to measure individuals' relationship to eating with respect to the dimensions of restraint (21 items), disinhibition (16 items), and hunger (14 items). The multiple-choice questionnaire asks about typical eating behaviors, and responses are scored 0 or 1 and summed. High scores indicate higher levels of disordered eating as it relates to restraint, disinhibition, and feelings of hunger, based on each respective section of the questionnaire [57].

\subsubsection{Salivary Cortisol Measurements}

Saliva was collected at home upon waking (saliva sample 1), 30 min post-waking (saliva sample 2), and at bedtime (saliva sample 14). Saliva was also collected 11 times during a test visit on study weeks 1 and 9. These samples were collected upon arrival (saliva sample 3) at the research center and at 30 min intervals after a morning oral glucose tolerance test (saliva samples 4-7), in the afternoon after a standard lunch (saliva samples 8 and 9), and then at $30 \mathrm{~min}$ intervals after the induction of the Trier Social Stress Test (TSST, saliva samples 10-13). Sample number 9 was taken immediately before initiating the stress test and served as the pre-TSST sample. The samples were collected using Salimetrics Oral Swabs. Participants put the swab in their mouth for 1-2 min in order to collect saliva and then deposited the swab into provided sample tubes. The sample tubes collected at home, after waking and before going to bed, were stored in the participant's refrigerator prior to returning the samples to the WHNRC for analysis, using an ELISA method (expanded-range high-sensitivity salivary cortisol kit, Salimetrics, State College, PA), which can detect cortisol concentrations ranging from 0.193 to $82.77 \mathrm{nmol} / \mathrm{L}(0.007-3.0 \mu \mathrm{g} / \mathrm{dL})$. The intra- and inter-assay coefficients of variability are $3.5 \%$ and $5.1 \%$, respectively.

To assess acute stress-related cortisol responsiveness, the TSST was administered for about $2 \mathrm{~h}$ after eating a standard lunch at each test visit on weeks 1 and 9. The TSST consists of two challenging tasks known to evoke moderate psychological stress and increases in plasma and salivary cortisol [58]: a speech task and a mental arithmetic task. Both of these tasks were performed in front of two judges (they were unfamiliar to the subjects) and a video camera (subjects were told that videos were retained and used only by research staff to evaluate the participant's behavior during the task). Following a rest period, participants were brought into a room and introduced to the judges who told them about the tasks they would be performing over the next $20 \mathrm{~min}$. Each subject was then be given $5 \mathrm{~min}$ to prepare her $5 \mathrm{~min}$ speech, after which time the judges would return and the speech would begin. Directly following the speech was a 5 min question-and-answer session, in which the subject was asked about her past work experience and experiences with managers and co-workers. After this session, subjects were given 5 min to count backwards in odd steps from a prime number (e.g., starting at 1022 and counting backwards by 13) as quickly and accurately as possible. If a mistake was made, the subject was asked to start from the beginning. 


\subsubsection{Physical Measurements}

Measurements of height, weight, and waist-to-hip ratio were collected to provide information about participants' anthropometric status. Participants were weighed wearing lightweight surgical scrubs using a calibrated electronic scale (Tanita BWB-627A Class III electronic scale; Toledo Scale), which were measured to the nearest $0.1 \mathrm{~kg}$. A wall-mounted stadiometer (model S100; Ayrton Corporation, Prior Lake, MN, USA) was used to measure the height to the nearest $0.1 \mathrm{~cm}$. These values were used to calculate BMI with the unit of $\mathrm{kg} / \mathrm{m}^{2}$. Waist and hip circumferences were measured in duplicate for accuracy with an anthropometric tape around the circumference of the area between the iliac crest and the rib cage for waist circumference, and at the maximum protuberance of the buttocks for hip circumference. A standard blood pressure cuff (GE DINAMAP vitals monitor; GE Healthcare, Chicago, IL, USA) placed on one arm was used to measure blood pressure.

\subsection{Statistical Analysis}

The SAS System software for Windows (release 9.4; Cary, NC, USA) was used to perform statistical analyses. Salivary cortisol concentrations were logarithm-transformed. To examine effects of the intervention on log salivary cortisol, we first applied a mixed model procedure (SAS MIXED procedure), which included fixed effects of diet group (DGA vs. TAD, intervention week (baseline (week 1) and week 9), saliva sample (1-14), all 2- and 3-factor interactions of the fixed effects, along with random effects of subject, subject by week, and subject by saliva sample to account for repeated measurements across the intervention week and the 14 saliva samples. Significant interactions between group and intervention week, and group, intervention week, and saliva sample were considered indicative of intervention effect. Fourteen subjects from each diet group completed both stress tasks (week 1 and week 9). However, saliva was still collected during all 14 time points on week 1 and week 9 from those subjects not participating in the stress task. Therefore, consistent with the intention-to-treat approach, we used all of the study participants in the analysis, except where noted as stated below. Baseline age, BMI, and education level were included as independent variables in the model. Because we also found baseline hunger (TFEQhunger), but not restrained eating or disinhibition from the TFEQ, to positively associate with salivary cortisol, we then also included the hunger score from the TFEQ as an independent variable in the final statistical model. Because one participant in the TAD group did not complete the baseline TFEQ, her data were dropped from the statistical analysis. Therefore, in the final model that included hunger, there were 22 subjects in the DGA group and 21 in the TAD group. Since the difference between the pre-intervention ("habitual") diet and the intervention diet (DGA; TAD) differed in magnitude for each subject, we hypothesized that these differences in dietary macronutrient shifts may possibly moderate the effects of the intervention on 8-week change in salivary cortisol and cortisol responsiveness. To explore whether intervention-based shifts in carbohydrate, protein, and fat consumption might moderate the effects of the diet intervention on salivary cortisol, we applied the above statistical model, but also included, one at a time, the intervention-based change in each of these macronutrients and their interactions with diet group, intervention week, saliva sample in the model. We observed a significant 4 -factor interaction between diet group, intervention week, saliva sample, and change in carbohydrate intake, suggesting that effects of diet depended not only on week and saliva sample, but also on the level of change in carbohydrate intake. To better understand the nature of this interaction, we estimated the expected value of log cortisol for each combination of diet group, intervention week, and saliva sample at selected levels of change in carbohydrate (mean and 90th and 10th percentiles across all subjects), using the least-square means (LSMEANS) option in SAS. To statistically assess the nature of this interaction, from the same

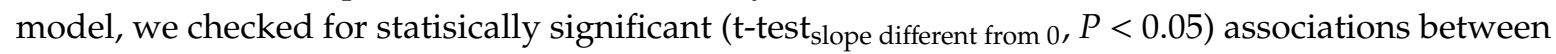
$\log$ salivary cortisol (nmol/L) and change in carbohydrate consumption. Using this same model, we also followed this examination up with specific contrasts to also test for significantly (t-test, $P<0.05$ ) different regression coefficients (slopes) between diet groups at each combination of intervention week and saliva sample. 


\section{Results}

In this randomized control diet intervention, 8-week change in salivary cortisol, examined over 14 daily time points throughout the day, did not appear to be affected by the diet intervention. We did not find a significant $(P>0.05)$ main effect of diet or diet-week, diet-saliva sample number, or diet-week-saliva sample interactions (Figure 1A). However, the intervention-based change in carbohydrate consumption appeared to moderate the effects of the diet intervention on salivary cortisol concentrations, particularly the cortisol concentrations just prior to and up to $120 \mathrm{~min}$ after the induction of the TSST (Figure 1B,C). Significant results were amplified when adding the hunger score from the TFEQ to the model. We found a significant $(P=0.0001) 4$-factor interaction between diet, intervention week, saliva sample number, and intervention-based change in carbohydrate consumption. To examine the nature of this interaction, we evaluated the salivary cortisol at low (10th percentile; +166 g), average $(+224 \mathrm{~g})$, and high (90th percentile; $+305 \mathrm{~g}$ ) levels of change in carbohydrate consumption. As shown in Figure 1B,C, it is evident that this interaction reflected a DGA-associated reduction in salivary cortisol at week 9 when the intervention led to higher (90th percentile) increases in the consumption of this macronutrient (Figure 1B). Figure 1C displays the 8-week change $(\Delta)$ in cortisol at each time point and for each of the low (10th percentile), mean, and high (90th percentile) levels of intervention-based changes in carbohydrate consumption. In support of these findings, we found significant inverse associations between log cortisol and change in carbohydrate in the DGA group, only at week 9 of the intervention, and at specific times during the day (Table 1). Similar to the above observations, these associations were present at times just prior to and up to $90 \mathrm{~min}$ after the stress test. The strongest and most significant association between log cortisol and change in carbohydrate occurred at the 30-min stress response time point $(\beta:-0.004 \pm 0.0015, P=0.009)$. We also found that this association at week 9 and the 30-min stress response time point significantly $(P=0.0236)$ differed between the DGA and TAD groups.
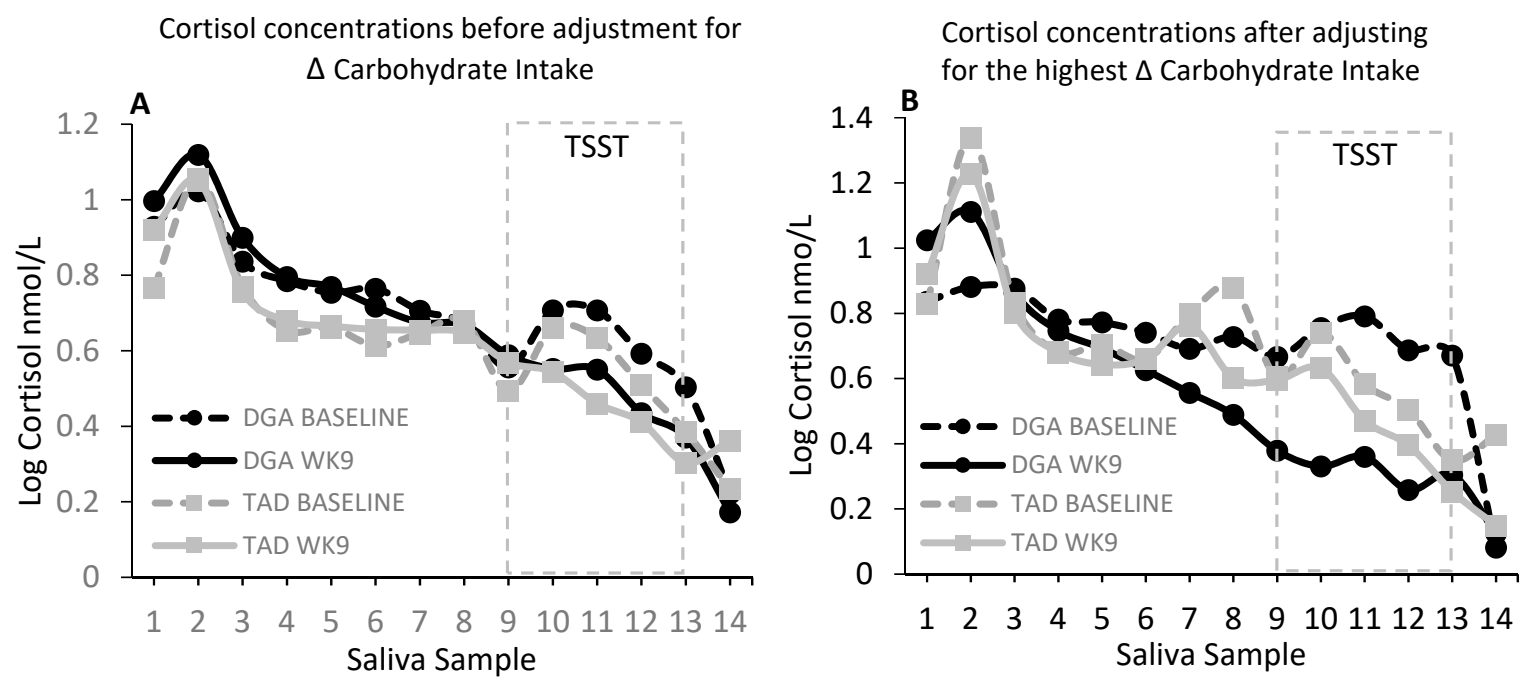

Figure 1. Cont. 


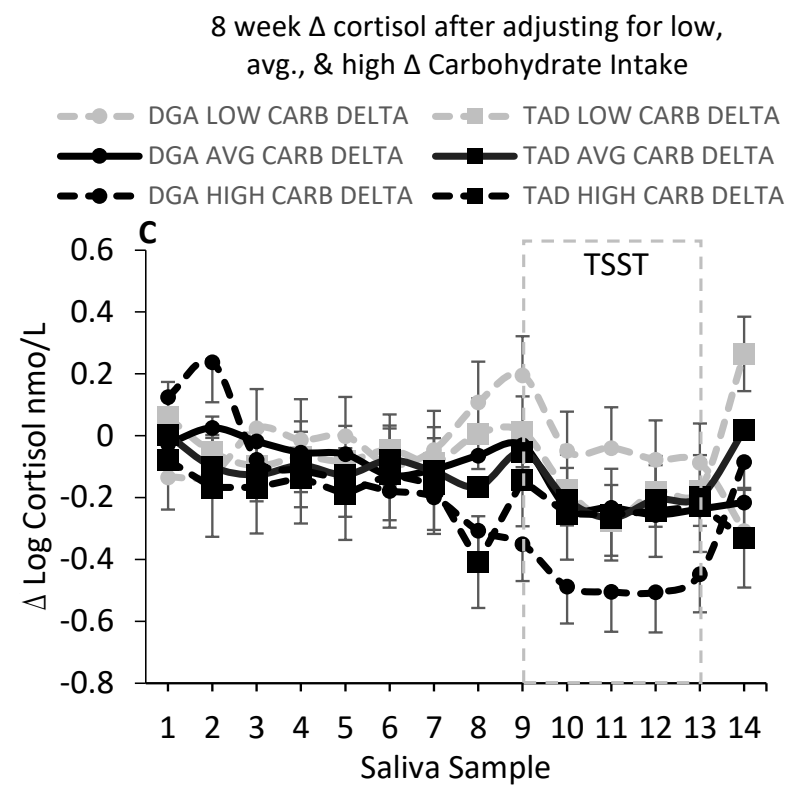

Figure 1. (A) shows salivary cortisol (nmol/L) at baseline (pre-intervention test week 1 ) and week 9 for each diet group at each time point from waking (sample 1) to bedtime (sample 14). There were no statistical differences in salivary cortisol between the diet groups (DGA, $N=22$; TAD, $N=21$ ). However, when accounting for inter-individual differences between the pre-intervention ("habitual") diet and the intervention diet, there was a significant $(P=0.0001)$ interaction between diet group, week, saliva sample, and magnitude of change in carbohydrate intake from habitual to the intervention level of intake. The significant $(P=0.0001)$ interaction between diet group, week, saliva sample, and level of change in carbohydrate intake was reflected primarily by a reduction in salivary cortisol just prior to the stress test (Trier Social Stress Test; TSST) and up to 120 min post-stress in the DGA (Dietary Guidelines for Americans) group that also had the highest increase (90th percentile) in carbohydrate consumption from the pre-intervention to the intervention period. (B) Salivary cortisol (nmol/L) at baseline and week 9 for each diet group at the highest increase (90th percentile) in carbohydrate consumption from the pre-intervention (habitual) to the intervention period. (C) The 8-week change $(\Delta)$ in salivary cortisol concentration $(\mathrm{nmol} / \mathrm{L})$. There was a significant $(P=0.0001)$ interaction between diet group, saliva sample, and level of change in total carbohydrate intake for the 8-week change $(\Delta)$ in salivary cortisol concentration. A low increase in CARB (total carbohydrate; $+166 \mathrm{~g}$ ) was taken as the 10th percentile increase in carbohydrate consumption from the pre-intervention to the intervention period; an AVG (average; middle 90th percentile) increase in carbohydrate $(+224 \mathrm{~g})$ was taken as the mean level increase in carbohydrate consumption from the pre-intervention to the intervention period; and a high increase in CARB was taken as the 90th percentile increase in carbohydrate $(+305 \mathrm{~g})$ from the pre-intervention to the intervention period. Baseline age, education, body mass index (BMI), and hunger score from the Three-Factor Eating Questionnaire were included as independent variables in all of the statistical models. For visual clarity, data shown in Figure 1A,B are adjusted means (least-square means; LSMEANS) only. For Figure 1C, LSMEANS \pm s.e. are presented. 
Table 1. * Slope estimates for association between log salivary cortisol concentration and $\Delta$ carbohydrate.

\begin{tabular}{|c|c|c|c|c|c|}
\hline Sample Time (Sample Number) & Diet & Intervention Week & Slope & S.E. & $P$-Value \\
\hline \multirow{2}{*}{ Pre-TSST (9) } & DGA & Baseline & 0.001463 & 0.001487 & 0.3266 \\
\hline & DGA & 9 & -0.00312 & 0.001487 & 0.0372 \\
\hline \multirow{2}{*}{30 min post-TSST (10) } & DGA & Baseline & 0.001142 & 0.001487 & 0.4434 \\
\hline & DGA & 9 & -0.0039 & 0.001487 & $0.0096^{* *}$ \\
\hline \multirow{2}{*}{$60 \mathrm{~min}$ post-TSST (11) } & DGA & Baseline & 0.001814 & 0.001507 & 0.2306 \\
\hline & DGA & 9 & -0.00312 & 0.001517 & 0.041 \\
\hline \multirow{2}{*}{90 min post-TSST (12) } & DGA & Baseline & 0.001689 & 0.001493 & 0.2596 \\
\hline & DGA & 9 & -0.00298 & 0.00152 & 0.0516 \\
\hline \multirow{2}{*}{$120 \mathrm{~min}$ post-TSST (13) } & DGA & Baseline & 0.002341 & 0.001492 & 0.1186 \\
\hline & DGA & 9 & -0.00193 & 0.001488 & 0.1955 \\
\hline \multirow{2}{*}{ Pre-TSST (9) } & TAD & Baseline & 0.000565 & 0.001402 & 0.687 \\
\hline & TAD & 9 & -0.00013 & 0.001438 & 0.93 \\
\hline \multirow{2}{*}{30 min post-TSST (10) } & TAD & Baseline & 0.000172 & 0.001402 & 0.9023 \\
\hline & TAD & 9 & 0.000992 & 0.001438 & 0.4908 \\
\hline \multirow{2}{*}{60 min post-TSST (11) } & TAD & Baseline & -0.00139 & 0.001402 & 0.3228 \\
\hline & TAD & 9 & 0.000077 & 0.001439 & 0.9571 \\
\hline \multirow{2}{*}{90 min post-TSST (12) } & TAD & Baseline & -0.00083 & 0.001405 & 0.5551 \\
\hline & TAD & 9 & -0.00017 & 0.001442 & 0.9073 \\
\hline \multirow{2}{*}{120 min post-TSST (13) } & TAD & Baseline & -0.00106 & 0.001406 & 0.4501 \\
\hline & TAD & 9 & -0.00041 & 0.001439 & 0.7742 \\
\hline
\end{tabular}

* The significant diet group-week-saliva sample- $\Delta$ carbohydrate interaction suggested the nature of the association between cortisol and $\Delta$ carbohydrate differed among diet groups (DGA, $N=22$; TAD, $N=21$ ), intervention week, and saliva samples. Therefore, we also used the mixed model procedure, accounting for repeated measurements, to estimate coefficients (slopes) for the relationship between log salivary cortisol $(\mathrm{nmol} / \mathrm{L})$ and magnitude of change $(\Delta)$ in carbohydrate consumption from the pre-intervention (habitual) to the diet intervention period as a continuous variable at each combination of diet group, intervention week, and saliva sample. The $P$-value in bold indicates that the slope was significantly different from 0 , while the double asterisk (**) indicates that the slopes for that week and sample number significantly differed between the DGA and TAD groups. Baseline age, education, BMI, and hunger score from the Three-Factor Eating Questionnaire were included as independent variables in the statistical model. TSST: Trier Social Stress Test; Pre-TSST: Saliva sample taken immediately prior to the stress test; DGA: Dietary Guidelines for Americans diet intervention group; TAD: typical American diet intervention group.

\section{Discussion}

\subsection{Differences in Dietary Carbohydrate Moderate Effects of the Diet Intervention on Salivary Cortisol}

Stress, stress-induced increases in circulating cortisol, and elevations in basal circulating cortisol are linked to disorders of mood and cognitive decline [58-62], and these effects may, in part, result from the propensity of stress and elevated cortisol concentrations to promote poor nutrition habits and reduce adherence to health-promoting diets, such as those based on the DGA. Therefore, such dietary effects of stress and cortisol can significantly limit the effectiveness of dietary recommendations in treating or preventing diseases such as type 2 diabetes. Furthermore, it is widely accepted that a healthy diet can play an important role in the management of cognitive, neuroendocrine, and autonomic responses to stress and consequently play an important role in the prevention of depression and other stress related diseases. Given this, it is surprising that specific, evidence-based, dietary recommendations for supporting stress management do not exist. This study is the first of its kind to utilize a randomized control trial model to compare effects of consuming DGA- or TAD-based diets on cortisol and stress-related cortisol responsiveness. In particular, very little is known about how whole food diets, such as those based on the DGA, influence circulating cortisol. 
There were no statistical differences between the diet groups in salivary cortisol at baseline or after 8 weeks. However, since the difference between the pre-intervention ("habitual") diet and the intervention diet (DGA; TAD) differed in magnitude for each subject, we hypothesized that the degree of change in dietary macronutrient differences may possibly moderate the effects of the intervention on 8 week change in salivary cortisol and cortisol responsiveness. When considering these differences in dietary carbohydrate from the pre-intervention (habitual) to the intervention period, our current findings suggest that increasing dietary carbohydrate, as part of a healthy whole food diet, dampens 8 -week changes in salivary cortisol, particularly during the period following the stress test. We did not observe this effect with dietary fat or protein.

Several studies have shown dietary sugar or carbohydrate to reduce stress-induced elevation in glucocorticoid hormones, such as corticosterone (rodents) and cortisol (human) [20-24], a phenomenon thought to physiologically explain and strengthen comfort eating or the stress-eating relationship $[25,26]$. A diet high in carbohydrate was shown to reduce cortisol and negative mood after stress [63], and carbohydrate loading was shown to increase performance and inhibit the typical cortisol increase in response to prolonged exercise [64]. Given the physiological link between the glucocorticoids and glucose regulation and preference for dietary carbohydrate, it is not surprising to observe an association between circulating cortisol and changes in carbohydrate consumption. However, our study uniquely suggests that these apparent effects of carbohydrate consumption may interact with the quality of the total diet being consumed. It is interesting that including the TFEQ hunger score in the interaction resulted in an amplified moderating effect of carbohydrate differentiation in stress response between the two diet groups. This may suggest that carbohydrate intake may have an attenuating effect on hunger which can, in turn, increase susceptibility to stress. We did not observe these dampening effects of increasing carbohydrate in the context of the TAD. The TAD used in this study was higher in saturated fat [50]. Previous studies have shown inductive effects of a high-fat diet on stress responsiveness including cortisol and corticosterone $[8,17,18]$. It is possible, therefore, that this inductive effect of increasing certain types of dietary fat may have countered the dampening effects of increasing carbohydrate intake on cortisol in the TAD group.

Alternatively, it was recently shown in a cross-sectional study of adolescents that higher adherence to a Mediterranean diet resulted in reduced inflammation and a disassociation between inflammatory cytokines and salivary cortisol [65]. Since high-fat diets can induce mild inflammation [66], it is possible the DGA diet provided a similar protective effect against inflammation and inflammatory-induced cortisol [67], compared to the higher-fat TAD. However, while the TAD was higher in saturated fat, we did not observe an association between salivary cortisol and the intervention-based change in dietary fat. A higher sodium consumption in the TAD may have also masked the cortisol lowering effects of increasing carbohydrate. Prior research suggests that increasing dietary sodium can elevate circulating cortisol. We previously showed that increasing sodium consumption is positively associated with markers of chronic stress, including higher $12 \mathrm{~h}$, overnight, urinary cortisol concentrations [68]. There also exists other evidence that increases in sodium intake or salt load can raise urinary cortisol [69-71], while restricting sodium intake appeared to reduce urinary cortisol [72]. On the other hand, there may have been a more permissive effect of the DGA diet itself, possibly through the effects of other nutrients on neurological systems that regulate cortisol production. For example, dietary vitamin D, which was higher in the DGA group [50], was shown to facilitate ongoing serotonergic activity in the brain [73], possibly by suppressing the serotonin reuptake transporter and inhibiting serotonin reuptake. The stress and cortisol reducing effects of carbohydrate consumption have also been thought to be mediated, in part, by enhanced serotonergic activity in the brain [74], which also may enhance negative feedback in the hypothalamic-pituitary-adrenal axis and reduce circulating cortisol $[62,74,75]$. These explanations are only speculative, but our results warrant mechanistic studies to determine how and why changes in dietary carbohydrate link to alterations in cortisol in the context of the DGA-based, but not TAD-based, whole food diets. 
Given the known detrimental health risks of chronic stress load, in part through heightened exposure to cortisol, these findings may have important clinical implications. Increases in cortisol and stress-associated cortisol responsiveness have been linked to elevated risk for central obesity, metabolic syndrome, cardiovascular disease, type 2 diabetes, depression, and other disorders of the brain $[60,76]$. Therefore, as it relates to managing unhealthy stress reactions and its effects on mental and metabolic health, it may be appropriate to consider carbohydrate intake, and perhaps even increasing intake in the context of a healthy whole food diet. Of course, in some cases, such as in diabetics, increasing carbohydrate consumption is not recommended. Our findings also suggest that, in the context of dieting or adopting a healthier diet, carbohydrate consumption may help to minimize dietary relapse due to the stress of restricting favorite, highly palatable comfort foods $[24,25,77]$. Chronic stress and over-exposure to the glucocorticoid hormone, cortisol, can increase preference for and drive to eat highly palatable, nutrient scarce foods [37], thereby reducing in some persons capacity for sustaining significant and durable improvements in diet quality. Chronic dieting and repeated attempts to avoid preferred foods, even with unsuccessful weight loss, has been shown to be associated with elevations in stress markers, and salivary and urinary cortisol, independent of BMI [54,55,78]. Our findings suggest that carbohydrate consumption as part of a healthy whole food diet may help minimize over-exposure to cortisol and its associated downstream effects, including increasing hunger for comfort foods. This has implications for individuals consuming highly carbohydrate-restrictive diets or individuals, for whom stress presents a significant barrier to consuming a whole food diet overall. Since the variable CARB represents degree of change from habitual diet, the results suggest that the degree of change to carbohydrate intake may affect circulating cortisol levels. Therefore, diets that include a drastic reduction in carbohydrates may precipitate stress-inductive effects. These results support the notion that carbohydrate-restrictive diets may have stress-inducing effects that may work counter to their ability to be sustainable. In these cases, if possible, it may be worthwhile incrementally increasing carbohydrate intake, if possible, to alleviate any stress-inductive effects.

\subsection{Limitations}

To our knowledge, this is the first controlled-feeding trial comparing the effects of a whole food diet with a more representative American diet on salivary cortisol and stress-related cortisol responsiveness. However, we acknowledge limitations associated with this trial, as previously reported [50]. The 8-week duration of this study is, to some degree, short and may not represent effects, or lack thereof, that may be observed over a longer period of time. In addition, we acknowledge that our study included a relatively small sample size. It should also be re-emphasized that, while our results suggest that the carbohydrate intake and diet group interacted to affect stress-related cortisol concentrations or responsiveness, we acknowledge that this diet group specific association between carbohydrate and cortisol during the week-9 stress test period cannot definitively be assumed to be linked to the stress response, since a subset of the participants did not participate in the stress test on both visits. Finally, as this study was conducted in women, it is important to note that our findings may not be generalized for men or individuals with normal glucose or lipid values.

\section{Conclusions}

This study provides further evidence for the health benefits of a DGA-based whole food diet. Furthermore, we add to a growing body of evidence supporting the potential effects of suppressive effects of dietary carbohydrate on circulating cortisol and stress-associated cortisol reactivity.

Such new information may help to inform an understanding of nutrition where key food groups facilitate improved adherence to often fleeting healthy changes in diet. Overall, these results support novel target areas for improving nutrition and disease prevention messaging.

Author Contributions: K.D.L. and N.L.K. contributed to the study design. H.S. and K.D.L. analyzed the data. All authors contributed to writing and editing the manuscript. Conceptualization, H.S., N.L.K. and K.D.L.; Methodology, H.S., N.L.K. and K.D.L.; Software, H.S. and K.D.L.; Validation, H.S., N.L.K. and K.D.L.; Formal 
Analysis, H.S. and K.D.L.; Investigation, H.S., N.L.K. and K.D.L.; Resources, H.S., N.L.K. and K.D.L.; Data Curation, H.S., N.L.K. and K.D.L.; Writing-Original Draft Preparation, H.S. and K.D.L.; Writing—Review \& Editing, H.S., N.L.K. and K.D.L.; Visualization, H.S. and K.D.L.; Supervision, H.S., N.L.K. and K.D.L.; Project Administration, N.L.K. and K.D.L.; Funding Acquisition, N.L.K. and K.D.L.

Funding: This research was supported with funding from a USDA Agricultural Research Service project (No.: 2032-51530-022-00-D), the National Dairy Council, and the Campbell Soup Company.

Acknowledgments: We would like to thank Jan Peerson for her expert advice on statistical analysis. The contents of this paper are solely the responsibility of the authors and do not represent the official view of the United States Department of Agriculture. The USDA is an equal opportunity provider and employer.

Conflicts of Interest: The authors declare no conflict of interest.

\section{References}

1. Sarris, J.; Logan, A.C.; Akbaraly, T.N.; Amminger, G.P.; Balanza-Martinez, V.; Freeman, M.P.; Hibbeln, J.; Matsuoka, Y.; Mischoulon, D.; Mizoue, T.; et al. Nutritional medicine as mainstream in psychiatry. Lancet Psychiatry 2015, 2, 271-274. [CrossRef]

2. Brody, S.; Preut, R.; Schommer, K.; Schurmeyer, T.H. A randomized controlled trial of high dose ascorbic acid for reduction of blood pressure, cortisol, and subjective responses to psychological stress. Psychopharmacology 2002, 159, 319-324. [CrossRef] [PubMed]

3. Carter, J.R.; Schwartz, C.E.; Yang, H.; Joyner, M.J. Fish oil and neurovascular reactivity to mental stress in humans. Am. J. Physiol. Regul. Integr. Comp. Physiol. 2013, 304, R523-R530. [CrossRef]

4. Harris, E.; Kirk, J.; Rowsell, R.; Vitetta, L.; Sali, A.; Scholey, A.B.; Pipingas, A. The effect of multivitamin supplementation on mood and stress in healthy older men. Hum. Psychopharmacol. 2011, 26, 560-567. [CrossRef] [PubMed]

5. Hellhammer, J.; Fries, E.; Buss, C.; Engert, V.; Tuch, A.; Rutenberg, D.; Hellhammer, D. Effects of soy lecithin phosphatidic acid and phosphatidylserine complex (PAS) on the endocrine and psychological responses to mental stress. Stress 2004, 7, 119-126. [CrossRef]

6. Hellhammer, J.; Hero, T.; Franz, N.; Contreras, C.; Schubert, M. Omega-3 fatty acids administered in phosphatidylserine improved certain aspects of high chronic stress in men. Nutr. Res. 2012, 32, 241-250. [CrossRef]

7. Hellhammer, J.; Vogt, D.; Franz, N.; Freitas, U.; Rutenberg, D. A soy-based phosphatidylserine/ phosphatidic acid complex (PAS) normalizes the stress reactivity of hypothalamus-pituitary-adrenal-axis in chronically stressed male subjects: A randomized, placebo-controlled study. Lipids Health Dis. 2014, 13, 121. [CrossRef]

8. Jakulj, F.; Zernicke, K.; Bacon, S.L.; van Wielingen, L.E.; Key, B.L.; West, S.G.; Campbell, T.S. A high-fat meal increases cardiovascular reactivity to psychological stress in healthy young adults. J. Nutr. 2007, 137, 935-939. [CrossRef]

9. Kennedy, D.O.; Veasey, R.; Watson, A.; Dodd, F.; Jones, E.; Maggini, S.; Haskell, C.F. Effects of high-dose $B$ vitamin complex with vitamin $C$ and minerals on subjective mood and performance in healthy males. Psychopharmacology 2010, 211, 55-68. [CrossRef]

10. Long, S.J.; Benton, D. Effects of vitamin and mineral supplementation on stress, mild psychiatric symptoms, and mood in nonclinical samples: A meta-analysis. Psychosom. Med. 2013, 75, 144-153. [CrossRef]

11. Markus, C.R.; Olivier, B.; de Haan, E.H. Whey protein rich in alpha-lactalbumin increases the ratio of plasma tryptophan to the sum of the other large neutral amino acids and improves cognitive performance in stress-vulnerable subjects. Am. J. Clin. Nutr. 2002, 75, 1051-1056. [CrossRef] [PubMed]

12. Markus, C.R.; Olivier, B.; Panhuysen, G.E.; Van Der Gugten, J.; Alles, M.S.; Tuiten, A.; Westenberg, H.G.; Fekkes, D.; Koppeschaar, H.F.; de Haan, E.E. The bovine protein alpha-lactalbumin increases the plasma ratio of tryptophan to the other large neutral amino acids, and in vulnerable subjects raises brain serotonin activity, reduces cortisol concentration, and improves mood under stress. Am. J. Clin. Nutr. 2000, 71, 1536-1544. [CrossRef] [PubMed]

13. Sayegh, R.; Schiff, I.; Wurtman, J.; Spiers, P.; McDermott, J.; Wurtman, R. The effect of a carbohydrate-rich beverage on mood, appetite, and cognitive function in women with premenstrual syndrome. Obstet. Gynecol. 1995, 86 Pt 1, 520-528. [CrossRef]

14. Schubert, M.; Contreras, C.; Franz, N.; Hellhammer, J. Milk-based phospholipids increase morning cortisol availability and improve memory in chronically stressed men. Nutr. Res. 2011, 31, 413-420. [CrossRef] 
15. Schult, J.; Hero, T.; Hellhammer, J. Effects of powdered fertilized eggs on the stress response. Clin. Nutr. (Edinb. Scotl.) 2010, 29, 255-260. [CrossRef] [PubMed]

16. Wurtman, J.J.; Brzezinski, A.; Wurtman, R.J.; Laferrere, B. Effect of nutrient intake on premenstrual depression. Am. J. Obstet. Gynecol. 1989, 161, 1228-1234. [CrossRef]

17. Tannenbaum, B.M.; Brindley, D.N.; Tannenbaum, G.S.; Dallman, M.F.; McArthur, M.D.; Meaney, M.J. High-fat feeding alters both basal and stress-induced hypothalamic-pituitary-adrenal activity in the rat. Am. J. Physiol. 1997, 273, E1168-E1177. [CrossRef] [PubMed]

18. Legendre, A.; Harris, R.B. Exaggerated response to mild stress in rats fed high-fat diet. Am. J. Physiol. Regul. Integr. Comp. Physiol. 2006, 291, R1288-R1294. [CrossRef]

19. Hilimire, M.R.; DeVylder, J.E.; Forestell, C.A. Fermented foods, neuroticism, and social anxiety: An interaction model. Psychiatry Res. 2015, 228, 203-208. [CrossRef]

20. Foster, M.T.; Warne, J.P.; Ginsberg, A.B.; Horneman, H.F.; Pecoraro, N.C.; Akana, S.F.; Dallman, M.F. Palatable foods, stress, and energy stores sculpt corticotropin-releasing factor, adrenocorticotropin, and corticosterone concentrations after restraint. Endocrinology 2009, 150, 2325-2333. [CrossRef]

21. Laugero, K.D. Reinterpretation of basal glucocorticoid feedback: Implications to behavioral and metabolic disease. Vitam. Horm. 2004, 69, 1-29. [PubMed]

22. Laugero, K.D.; Bell, M.E.; Bhatnagar, S.; Soriano, L.; Dallman, M.F. Sucrose ingestion normalizes central expression of corticotropin-releasing-factor messenger ribonucleic acid and energy balance in adrenalectomized rats: A glucocorticoid-metabolic-brain axis? Endocrinology 2001, 142, 2796-2804. [CrossRef] [PubMed]

23. Laugero, K.D.; Gomez, F.; Manalo, S.; Dallman, M.F. Corticosterone infused intracerebroventricularly inhibits energy storage and stimulates the hypothalamo-pituitary axis in adrenalectomized rats drinking sucrose. Endocrinology 2002, 143, 4552-4562. [CrossRef] [PubMed]

24. Tryon, M.S.; Stanhope, K.L.; Epel, E.S.; Mason, A.E.; Brown, R.; Medici, V.; Havel, P.J.; Laugero, K.D. Excessive Sugar Consumption May Be a Difficult Habit to Break: A View from the Brain and Body. J. Clin. Endocrinol. Metab. 2015, 100, 2239-2247. [CrossRef]

25. Dallman, M.F.; Pecoraro, N.; Akana, S.F.; La Fleur, S.E.; Gomez, F.; Houshyar, H.; Bell, M.E.; Bhatnagar, S.; Laugero, K.D.; Manalo, S. Chronic stress and obesity: A new view of "comfort food". Proc. Natl. Acad. Sci. USA 2003, 100, 11696-11701. [CrossRef]

26. Ulrich-Lai, Y.M. Self-medication with sucrose. Curr. Opin. Behav. Sci. 2016, 9, 78-83. [CrossRef]

27. United States Department of Agriculture. Report of the Dietary Guidelines Advisory Committee on the Dietary Guidelines for Americans; USDA: Washington, DC, USA, 2015.

28. Van Horn, L.; Carson, J.A.S.; Appel, L.J.; Burke, L.E.; Economos, C.; Karmally, W.; Lancaster, K.; Lichtenstein, A.H.; Johnson, R.K.; Thomas, R.J.; et al. Recommended Dietary Pattern to Achieve Adherence to the American Heart Association/American College of Cardiology (AHA/ACC) Guidelines: A Scientific Statement from the American Heart Association. Circulation 2016, 134, e505-e529. [CrossRef]

29. Franz, M.J.; VanWormer, J.J.; Crain, A.L.; Boucher, J.L.; Histon, T.; Caplan, W.; Bowman, J.D.; Pronk, N.P. Weight-Loss Outcomes: A Systematic Review and Meta-Analysis of Weight-Loss Clinical Trials with a Minimum 1-Year Follow-Up. J. Am. Diet. Assoc. 2007, 107, 1755-1767. [CrossRef]

30. Look AHEAD Research Group. Association of the magnitude of weight loss and changes in physical fitness with long-term cardiovascular disease outcomes in overweight or obese people with type 2 diabetes: A post-hoc analysis of the Look AHEAD randomised clinical trial. Lancet Diabetes Endocrinol. 2016, 4, 913-921. [CrossRef]

31. Berk, K.A.; Buijks, H.I.M.; Verhoeven, A.J.M.; Mulder, M.T.; Özcan, B.; van 't Spijker, A.; Timman, R.; Busschbach, J.J.; Sijbrands, E.J. Group cognitive behavioural therapy and weight regain after diet in type 2 diabetes: Results from the randomised controlled POWER trial. Diabetologia 2018, 61, 790-799. [CrossRef]

32. Look AHEAD Research Group. Eight-year weight losses with an intensive lifestyle intervention: The look AHEAD study. Obesity 2014, 22, 5-13. [CrossRef]

33. Appelhans, B.M.; French, S.A.; Pagoto, S.L.; Sherwood, N.E. Managing temptation in obesity treatment: A neurobehavioral model of intervention strategies. Appetite 2016, 96, 268-279. [CrossRef] [PubMed]

34. Elfhag, K.; Rössner, S. Who succeeds in maintaining weight loss? A conceptual review of factors associated with weight loss maintenance and weight regain. Obes. Rev. 2005, 6, 67-85. [CrossRef] [PubMed] 
35. MacLean, P.S.; Wing, R.R.; Davidson, T.; Epstein, L.; Goodpaster, B.; Hall, K.D.; Levin, B.E.; Perri, M.G.; Rolls, B.J.; Rosenbaum, M.; et al. NIH working group report: Innovative research to improve maintenance of weight loss. Obesity 2015, 23, 7-15. [CrossRef] [PubMed]

36. Wing, R.R.; Papandonatos, G.; Fava, J.L.; Gorin, A.A.; Phelan, S.; McCaffery, J.; Tate, D.F. Maintaining large weight losses: The role of behavioral and psychological factors. J. Consult. Clin. Psychol. 2008, 76, 1015-1021. [CrossRef] [PubMed]

37. Adam, T.C.; Epel, E.S. Stress, eating and the reward system. Physiol. Behav. 2007, 91, 449-458. [CrossRef]

38. Dallman, M.F.; la Fleur, S.E.; Pecoraro, N.C.; Gomez, F.; Houshyar, H.; Akana, S.F. Minireview: Glucocorticoids-food intake, abdominal obesity, and wealthy nations in 2004. Endocrinology 2004, 145, 2633-2638. [CrossRef]

39. Dixon, L.B.; Cronin, F.J.; Krebs-Smith, S.M. Let the pyramid guide your food choices: Capturing the total diet concept. J. Nutr. 2001, 131, 461s-472s. [CrossRef]

40. George, G.C.; Milani, T.J.; Hanss-Nuss, H.; Freeland-Graves, J.H. Compliance with dietary guidelines and relationship to psychosocial factors in low-income women in late postpartum. J. Am. Diet. Assoc. 2005, 105, 916-926. [CrossRef]

41. American Psychological Association. Stress in America: 2013; American Psychological Association: Washington, DC, USA, 2013.

42. Dallman, M.F. Stress-induced obesity and the emotional nervous system. Trends Endocrinol. Metab. TEM 2010, 21, 159-165. [CrossRef]

43. Murray, S.; Tulloch, A.; Gold, M.S.; Avena, N.M. Hormonal and neural mechanisms of food reward, eating behaviour and obesity. Nat. Rev. Endocrinol. 2014, 10, 540-552. [CrossRef]

44. Wansink, B. From mindless eating to mindlessly eating better. Physiol. Behav. 2010, 100, 454-463. [CrossRef]

45. Brown, K.W.; Ryan, R.M.; Creswell, J.D. Mindfulness: Theoretical Foundations and Evidence for its Salutary Effects. Psychol. Inq. 2007, 18, 211-237. [CrossRef]

46. American Psychological Association, A.P. Stress in America: The State of Our Nation. Stress in AmericaTM Survey; American Psychological Association: Washington, DC, USA, 2017.

47. Saad, L. Eight in 10 Americans Afflicted by Stress; Gallup: Washington, DC, USA, 2017.

48. Mason, A.E.; Epel, E.S.; Aschbacher, K.; Lustig, R.H.; Acree, M.; Kristeller, J.; Cohn, M.; Dallman, M.; Moran, P.J.; Bacchetti, P.; et al. Reduced reward-driven eating accounts for the impact of a mindfulness-based diet and exercise intervention on weight loss: Data from the SHINE randomized controlled trial. Appetite 2016, 100, 86-93. [CrossRef] [PubMed]

49. Mason, A.E.; Epel, E.S.; Kristeller, J.; Moran, P.J.; Dallman, M.; Lustig, R.H.; Acree, M.; Bacchetti, P.; Laraia, B.A.; Hecht, F.M.; et al. Effects of a mindfulness-based intervention on mindful eating, sweets consumption, and fasting glucose levels in obese adults: Data from the SHINE randomized controlled trial. J. Behav. Med. 2016, 39, 201-213. [CrossRef]

50. Krishnan, S.; Adams, S.H.; Allen, L.H.; Laugero, K.D.; Newman, J.W.; Stephensen, C.B.; Burnett, D.J.; Witbracht, M.; Welch, L.C.; Que, E.S.; et al. A Randomized Controlled Feeding Trial Based on the Dietary Guidelines for Americans on Cardiometabolic Health Indices. Am. J. Clin. Nutr. 2018, 108, 266-278. [CrossRef] [PubMed]

51. Subar, A.F.; Kirkpatrick, S.I.; Mittl, B.; Zimmerman, T.P.; Thompson, F.E.; Bingley, C.; Willis, G.; Islam, N.G.; Baranowski, T.; McNutt, S. The Automated Self-Administered 24-h dietary recall (ASA24): A resource for researchers, clinicians, and educators from the National Cancer Institute. J. Acad. Nutr. Diet. 2012, 112, 1134-1137. [CrossRef] [PubMed]

52. Firk, C.; Markus, C.R. Mood and cortisol responses following tryptophan-rich hydrolyzed protein and acute stress in healthy subjects with high and low cognitive reactivity to depression. Clin. Nutr. (Edinb. Scotl.) 2009, 28, 266-271. [CrossRef]

53. McAllister, M.J.; Webb, H.E.; Tidwell, D.K.; Smith, J.W.; Fountain, B.J.; Schilling, M.W.; Williams, R.D., Jr. Exogenous Carbohydrate Reduces Cortisol Response from Combined Mental and Physical Stress. Int. J. Sports Med. 2016, 37, 1159-1165. [CrossRef]

54. Anderson, D.A.; Shapiro, J.R.; Lundgren, J.D.; Spataro, L.E.; Frye, C.A. Self-reported dietary restraint is associated with elevated levels of salivary cortisol. Appetite 2002, 38, 13-17. [CrossRef]

55. McLean, J.A.; Barr, S.I.; Prior, J.C. Cognitive dietary restraint is associated with higher urinary cortisol excretion in healthy premenopausal women. Am. J. Clin. Nutr. 2001, 73, 7-12. [CrossRef] 
56. Rutters, F.; Nieuwenhuizen, A.G.; Lemmens, S.G.; Born, J.M.; Westerterp-Plantenga, M.S. Hyperactivity of the HPA axis is related to dietary restraint in normal weight women. Physiol. Behav. 2009, 96, 315-319. [CrossRef] [PubMed]

57. Bond, M.J.; McDowell, A.J.; Wilkinson, J.Y. The measurement of dietary restraint, disinhibition and hunger: An examination of the factor structure of the Three Factor Eating Questionnaire (TFEQ). Int. J. Obes. Relat. Metab. Disord. 2001, 25, 900-906. [CrossRef] [PubMed]

58. Kirschbaum, C.; Pirke, K.M.; Hellhammer, D.H. The 'Trier Social Stress Test'-a tool for investigating psychobiological stress responses in a laboratory setting. Neuropsychobiology 1993, 28, 76-81. [CrossRef] [PubMed]

59. McEwen, B.S. Protection and damage from acute and chronic stress: Allostasis and allostatic overload and relevance to the pathophysiology of psychiatric disorders. Ann. N. Y. Acad. Sci. 2004, 1032, 1-7. [CrossRef]

60. Sharma, S.T.; Nieman, L.K.; Feelders, R.A. Comorbidities in Cushing's disease. Pituitary 2015, 18, $188-194$. [CrossRef]

61. Young, A.H. Cortisol in mood disorders. Stress 2004, 7, 205-208. [CrossRef]

62. Seckl, J.R.; Fink, G. Use of in situ hybridization to investigate the regulation of hippocampal corticosteroid receptors by monoamines. J. Steroid Biochem. Mol. Biol. 1991, 40, 685-688. [CrossRef]

63. Markus, R.; Panhuysen, G.; Tuiten, A.; Koppeschaar, H. Effects of food on cortisol and mood in vulnerable subjects under controllable and uncontrollable stress. Physiol. Behav. 2000, 70, 333-342. [CrossRef]

64. Deuster, P.A.; Singh, A.; Hofmann, A.; Moses, F.M.; Chrousos, G.C. Hormonal responses to ingesting water or a carbohydrate beverage during a $2 \mathrm{~h}$ run. Med. Sci. Sports Exerc. 1992, 24, 72-79. [CrossRef]

65. Carvalho, K.M.B.; Ronca, D.B.; Michels, N.; Huybrechts, I.; Cuenca-Garcia, M.; Marcos, A.; Molnár, D.; Dallongeville, J.; Manios, Y.; Schaan, B.D.; et al. Does the Mediterranean Diet Protect against Stress-Induced Inflammatory Activation in European Adolescents? The HELENA Study. Nutrients 2018, 10, 1770. [CrossRef]

66. Cani, P.D.; Amar, J.; Iglesias, M.A.; Poggi, M.; Knauf, C.; Bastelica, D.; Neyrinck, A.M.; Fava, F.; Tuohy, K.M.; Chabo, C.; et al. Metabolic endotoxemia initiates obesity and insulin resistance. Diabetes 2007, 56, 1761-1772. [CrossRef] [PubMed]

67. Bethin, K.E.; Vogt, S.K.; Muglia, L.J. Interleukin-6 is an essential, corticotropin-releasing hormone-independent stimulator of the adrenal axis during immune system activation. Proc. Natl. Acad. Sci. USA 2000, 97, 9317-9322. [CrossRef]

68. Soltani, H.; Keim, N.L.; Laugero, K.D. Diet Quality for Sodium and Vegetables Mediate Effects of Whole Food Diets on 8-Week Changes in Stress Load. Nutrients 2018, 10, 1606. [CrossRef]

69. Baudrand, R.; Campino, C.; Carvajal, C.A.; Olivieri, O.; Guidi, G.; Faccini, G.; Vohringer, P.A.; Cerda, J.; Owen, G.; Kalergis, A.M.; et al. High sodium intake is associated with increased glucocorticoid production, insulin resistance and metabolic syndrome. Clin. Endocrinol. 2014, 80, 677-684. [CrossRef]

70. Ehrlich, E.N.; Lugibihl, K.; Laves, M.; Janulis, M. Reciprocal Variations in Urinary Cortisol and Aldosterone in Response to Increased Salt Intake in Humans. J. Clin. Endocrinol. Metab. 1966, 26, 1160-1169. [CrossRef] [PubMed]

71. Wambach, G.; Bleienheuft, C.; Bonner, G. Sodium loading raises urinary cortisol in man. J. Endocrinol. Investig. 1986, 9, 257-259. [CrossRef] [PubMed]

72. Lewicka, S.; Nowicki, M.; Vecsei, P. Effect of sodium restriction on urinary excretion of cortisol and its metabolites in humans. Steroids 1998, 63, 401-405. [CrossRef]

73. Sabir, M.S.; Haussler, M.R.; Mallick, S.; Kaneko, I.; Lucas, D.A.; Haussler, C.A.; Whitfield, G.K.; Jurutka, P.W. Optimal vitamin D spurs serotonin: 1,25-dihydroxyvitamin D represses serotonin reuptake transport (SERT) and degradation (MAO-A) gene expression in cultured rat serotonergic neuronal cell lines. Genes Nutr. 2018, 13, 19. [CrossRef]

74. Markus, C.R. Dietary amino acids and brain serotonin function; implications for stress-related affective changes. Neuromol. Med. 2008, 10, 247-258. [CrossRef]

75. Dziurkowska, E.; Wesolowski, M.; Dziurkowski, M. Salivary cortisol in women with major depressive disorder under selective serotonin reuptake inhibitors therapy. Arch. Womens Ment. Health 2013, 16, 139-147. [CrossRef] [PubMed]

76. Cohen, S.; Janicki-Deverts, D.; Miller, G.E. Psychological stress and disease. JAMA 2007, 298, 1685-1687. [CrossRef] [PubMed] 
77. Tryon, M.S.; DeCant, R.; Laugero, K.D. Having your cake and eating it too: A habit of comfort food may link chronic social stress exposure and acute stress-induced cortisol hyporesponsiveness. Physiol. Behav. 2013, 114-115, 32-37. [CrossRef] [PubMed]

78. Rideout, C.A.; Linden, W.; Barr, S.I. High cognitive dietary restraint is associated with increased cortisol excretion in postmenopausal women. J. Gerontol. Ser. A Biol. Sci. Med. Sci. 2006, 61, 628-633. [CrossRef] [PubMed]

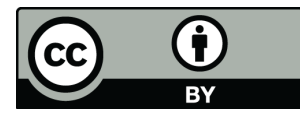

(C) 2019 by the authors. Licensee MDPI, Basel, Switzerland. This article is an open access article distributed under the terms and conditions of the Creative Commons Attribution (CC BY) license (http://creativecommons.org/licenses/by/4.0/). 